\title{
THE PRODUCTION PROCESS OF SPRING BARLEY UNDER THE INOCULATION WITH MIKROHUMIN WITH OPTIMIZED PLANT HORMONES CONTENT
}

\section{S. B. Dimova}

The success of pre-seed inoculation with biological products, bio-agents of which are microorganisms that are able to form associations with plants, depends on the initial conditions of interaction of introduced bacteria with the roots of juvenile plants. This process can be affected by several factors. Today there are enough experimental data which prove that growth substances - phytohormones (auxins and cytokinins first of all) occupy a special place in the regulation of the relationships of associative nitrogen fixers and cereal plants $[1 ; 2]$.

In this regard, obvious is the need to optimize the content of these substances in microbial preparations that will help receive fertilizers with high and stable performance. Pre-seed inoculation with biological products containing optimum amount of physiologically active substances will provide an opportunity to intensify the formation of effective associations of microorganisms with plants.

In previous studies we set optimal parameters of phytohormones content to enhance the activity of individual growth-stimulating activity of particular microbial drugs (including Mikrohumin) through biotesting. The objective of this study was to test the efficiency of biological preparation Mikrohumin with optimized content of physiologically active substances.

Materials and methods. During the vegetative experiment the effectiveness of pre-seed inoculation of spring barley of Hosia variety with the suspension containing nitrogen-fixing associative bacteria Azospirillum brasilense 410 (Mikrohumin bio-agents) was studied as well as with the same suspension combined with the solution of phytohormones (model of Mikrohumin microbial drug with optimized content of phytohormones). The content of indoleacetic acid (IAA) and cytokinin (zeatin and zeatin riboside) in investigated preparations was determined by solid phase ELISA method [3; 4].

Background phytohormones content in bacterial suspensions composed $0.75 \mathrm{~g} / \mathrm{cm}^{3}$ of IAA and $0.22 \mathrm{~g} / \mathrm{cm}^{3}$ of cytokinins. Optimized against phytohormonal load preparation contained $2.63 \mathrm{~g} / \mathrm{cm}^{3}$ of IAA and $0.56 \mathrm{~g} / \mathrm{cm}^{3}$ of cytokinins.

The experiment was carried out in a vegetative house in vessels with the capacity of $1 \mathrm{dm}^{3}$ on sod-podzolic silty-sabulous soil $\left(\mathrm{rNs}_{\mathrm{ol}}\right.$. 7.2 , humus - $1.02 \% ; \mathrm{P}_{2} \mathrm{O}_{5}-330 \mathrm{mg} / \mathrm{kg} ; \mathrm{K}_{2} \mathrm{O}-$ $148 \mathrm{mg} / \mathrm{kg}$ ). Prianishnikov mixture with half a dose of nitrogen was administered to the soil before sowing, given the inoculation with associative nitrogen-fixing bacteria $A$. brasilense 410, able to improve barley plant nitrogen nutrition.

Above-ground mass of plants was determined by gravimetrically after drying to constant indicators. The mass of roots was determined by washing the from monoliths, followed by drying to constant weight, chlorophyll content in leaves spectrophotometrically [5], protein content - by Lowry method [6]. Potential nitrogen fixation activity was determined in rhizospheric soil with the addition of glucose solution $[7 ; 8]$, and on the washed roots of spring barley - in semisolid Dobereiner culture medium [9]. At this the acetylene reduction was determined at chromatograph "Chrom-4" with a flame ionization detector on the column with Porapak Q. The potential denitrification activity in rhizospheric soil and washed roots was studied by acetylene method while adding glucose solution and potassium nitrate [10]. The reduction of nitrous oxide was determined at chromatograph "Tsvet-60 M" with thermal conductivity detector on the column with Porapak Q sorbent. Statistical analysis of the results was performed by Dospiekhov [11].

Thus, it was found that the combination of pre-seed inoculation with the optimum amount of phytohormones positively affects the development of spring barley plants in early stages of organogenesis. At this, phytohormones are an additional factor of positive influence on plants. The use of microbial preparation with optimized content of phytohormones $\left(2.63 \mathrm{~g} / \mathrm{cm}^{3}\right.$ of IAA and 0.56 $\mathrm{g} / \mathrm{cm}^{3}$ of cytokinins) affects the biological 
activity in barley plants rhizosphere - namely, positively impacts the process of biological nitrogen transformation in the root zone. It can provide additional nitrogen nutrition, promotes root system and aerial parts development, the formation of photosynthetic apparatus of plants and protein synthesis.

The method for producing microbial preparation was offered whereby the essential phytohormones are added to the microbial component of the preparation in the amounts previously set by biotesting. 